\title{
O ESTÁGIO SUPERVISIONADO EM GESTÃO: UMA PRÁTICA DE ENSINO E DE FORMAÇÃO NA PERSPECTIVA DEMOCRÁTICA
}

\author{
Helen Parnes Miranda, Thamires Marx, Andressa Graziele Brandt \\ Instituto Federal Catarinense \\ DOI: $10.15628 /$ rbept.2018.7512
}

Artigo submetido em jul/2018 e aceito em ago/2018

\begin{abstract}
RESUMO
O presente texto é resultado da prática de ensino, realizada na disciplina de Estágio Supervisionado em Gestão, no curso de licenciatura em Pedagogia, do Instituto Federal Catarinense- Campus Camboriú. Delineou-se como objetivo analisar e descrever o projeto de intervenção do estágio em gestão realizado pela professora formadora com os licenciandos em uma escola da rede estadual de Santa Catarina. Apresenta-se como questão central: como o estágio curricular supervisionado em gestão, organiza seus espaços teóricos e práticos em interconexão com os contextos escolares. O referencial teórico contempla três chaves conceituais: i) a gestão democrática como base do conhecimento profissional docente (PARO, 2016; e LAVAL, 2004); a atuação do Grêmio Estudantil MENDES, 2011); e iii) o protagonismo juvenil nas escolas (FERRETI; ZIBAS e TARTUCE, 2004). É uma pesquisa de abordagem qualitativa-descritiva, com desenvolvimento de análise documental do projeto de intervenção elaborado pelos licenciados. Este trabalho se deterá na análise da elaboração e socialização do relatório e projeto de intervenção acerca da temática o protagonismo juvenil na gestão colaborativa.
\end{abstract}

Palavras-Chave: Estágio Supervisionado em Gestão. Prática de Ensino. Gestão Democrática. Curso de Licenciatura em Pedagogia. Grêmio Estudantil.

\section{THE STUDY SUPERVISED IN MANAGEMENT: A PRACTICE OF EDUCATION AND TRAINING IN THE PERSPECTIVE OF DEMOCRATIC MANAGEMENT}

\begin{abstract}
The present text is a result of the teaching practice, carried out in the discipline of Supervised Internship in Management, in the degree course in Pedagogy, Federal Institute Catarinense Campus Camboriú. The purpose of this study was to analyze and describe the intervention project of internships in management carried out by the trainer teacher with the graduates in a school of the state network of Santa Catarina. It is presented as a central question: as the supervised curricular internship in management, organizes its theoretical and practical spaces in interconnection with the school contexts. The theoretical framework includes three conceptual keys: i) democratic management as the basis of professional teaching knowledge (PARO, 2016 and LAVAL, 2004); the performance of the Grêmio Estudantil MENDES, 2011); and iii) the role of youth in schools (FERRETI, ZIBAS and TARTUCE, 2004). It is a research of qualitative-descriptive approach, with development of documentary analysis of the intervention project elaborated by the graduates. This work will focus on the analysis of the elaboration and socialization of the report and intervention project on the theme of youth protagonism in collaborative management.
\end{abstract}

Keywords: Supervised Internship in Management. Teaching Practice. Democratic Management. Degree in Pedagogy. Student Guild. 


\section{INTRODUÇÃO}

O presente artigo foi desenvolvido no componente curricular de Estágio Supervisionado em Gestão, do Curso de Licenciatura em Pedagogia, do Instituto Federal Catarinense - Campus Camboriú e objetivou analisar descrever as atividades desenvolvi por uma dupla de acadêmicas sob orientação da professora de estágio.

Após as discussões realizadas em sala de aula sobre as características, dinâmicas, mecanismos, estratégias e estruturas da gestão escolar a partir de uma perspectiva democrática, as acadêmicas do Curso de Licenciatura em Pedagogia do Instituto Federal Catarinense - Campus Camboriú deram início as atividades do Estágio Supervisionado Obrigatório em Gestão.

A primeira etapa de estágio se constituiu por um período de seis dias de observação da gestão de uma instituição escolar estadual que oferta o Ensino Médio, o que totalizou uma carga horária de 24(vinte e quatro) horas. $\mathrm{Na}$ segunda etapa foi construído um projeto de intervenção a partir de temáticas propostas pelo campo de estágio. $\mathrm{E}$, por fim, na terceira etapa foi realizado o retorno do projeto às escolas, sendo apresentado aos gestores, como uma proposta de ação a ser colocada em prática pela equipe gestora da instituição concedente de estágio.

A instituição onde o referido estágio foi realizado é uma escola da rede estadual chamada Escola de Educação Básica (E.E.B.) Professor José Arantes, localizada na área central do município de Camboriú, no estado de Santa Catarina - SC. As observações da gestão escolar dessa instituição ocorreram no período de 11 à 18 de setembro de 2017 e a apresentação do projeto ocorreu no dia 13 de novembro de 2017.

Durante o período de observação, as gestoras relataram que os estudantes apresentavam interesse em instaurar um Grêmio Estudantil na escola e por isso elas gostariam que o projeto de intervenção de estágio fosse construído na perspectiva de orientar esse processo de implementação do mesmo. Por sua vez, o projeto de intervenção intitulado Grêmio Estudantil: uma oportunidade de aproximação entre gestão escolar e estudantes da Escola de Educação Básica Professor José Arantes, foi desenvolvido com enfoque no protagonismo juvenil na gestão colaborativa.

O presente artigo está dividido em três partes, a saber: I) apresentação do referencial teórico sobre a gestão democrática a partir das reflexões de Paro (2012) acerca da administração escolar comprometida com a transformação social. Após, traz-se um breve histórico, conceituações e considerações acerca do protagonismo juvenil no Brasil; ii) caracterização da E.E.B. Professor José Arantes; e iii) apresentação do projeto de intervenção 
de Estágio Supervisionado em Gestão. Por fim, são apresentadas as considerações finais e as referências.

\section{ADMINISTRAÇÃO ESCOLAR NA PERSPECTIVA DEMOCRÁTICA E O PROTAGONISMO JUVENIL}

Com a alteração nos meios de produção iniciada pelo movimento de industrialização no século XIX e XX em países como a Inglaterra, Alemanha, França, Estados Unidos, Japão, a sociedade sofreu várias alterações em suas dinâmicas culturais, com o destaque para o êxodo rural impulsionado pela crescente urbanização e o surgimento do capitalismo. Na segunda fase da revolução industrial, período já compartilhado pela sociedade brasileira a partir das últimas três décadas do século XIX, foi imposta a necessidade de qualificação de mão de obra mais complexa e, para efetivá-la, uma espécie de "a alfabetização da mão de obra", se coloca como indispensável. (PEIXOTO, OLIVEIRA, MAIO, s/d).

Não sem nexo, nesse mesmo período, tem-se a expansão da Educação Pública no Brasil. Porém, dado o contexto que a demandou e justificou sua criação e, especialmente, sua expansão, essa Educação se caracteriza muito mais como pública pelo perfil populacional que pretende cooptar como mão de obra do que pelo compromisso com o interesse público até então relegado. Assim, o sistema educacional se voltou à instrumentalização das técnicas e à disciplina necessária ao sistema produtivo do que à emancipação humana que se mostra, mais que nunca, indesejada para a perpetuação do sistema produtivo.

A influência do sistema produtivo na educação não é fenômeno exclusivo da realidade brasileira, o que proveria argumentos mais claros acerca da exploração que originou a atribuição de subdesenvolvimento do país. O taylorismo, teoria criada por um engenheiro, prevê a hierarquização e sistematização das tarefas que visa à produção em massa por meio da divisão de tarefas, da repetição do esforço e da alienação pelo trabalho. 0 fordismo, criado por um dono de empresa, constitui-se na inserção de mais um elemento otimizador ao taylorismo: a linha de montagem e a percepção da motivação produtiva do trabalhador pelo anseio ao consumo. (PEIXOTO, OLIVEIRA, MAIO, s/d).

As percepções sob o enfoque da engenharia e do gerenciamento empresarial demandavam uma especialização do trabalhador que só poderia ser prontamente atendida pelo direcionamento de todos os esforços educacionais ao ensino técnico, enfoque que não somente resiste a uma Educação mais humana e global, como que acaba por advogar contra ela, promovendo o outro fator de efetividade produtiva percebida por Taylor, a alienação para o trabalho. Essa especialização, no entanto, não somente constitui um estreitamento do olhar para um aprofundamento teórico-prático, mas promove a alienação e a subordinação acadêmica e científica, vez que o 
estudante só encontrará espaço de pesquisa na área que o sistema produtivo julga necessário, bem como se vê refém do redirecionamento educacional caso sua área de estudo se torne secundária.

Assim, percebe-se que o sistema produtivo introduz teorias e objetivos da administração empresarial na área educacional, transformando a escola em uma instituição de formação de mão de obra, em uma perspectiva que percebe a lógica mercadológica como reguladora do sistema social. De uma maneira geral, as indústrias têm objetivos diferentes da escola: a indústria visa à obtenção do produto e a escola tem como objetivo a socialização e construção do conhecimento. No entanto, podemos dizer que o conhecimento vira produto, a partir do momento que a perspectiva da escola é formar mão de obra para as indústrias. Talvez, possa ser nesse sentido que a gestão educacional se aproxime tanto da gestão empresarial, pois ambas buscam o aperfeiçoamento e o controle dos sujeitos, para que estes tenham 0 conhecimento necessário para produzir e por fim gerar o lucro.

É neste sentido que o sistema produtivo interfere na educação e principalmente nas políticas públicas que são revestidas de ideologias e influências políticas, revelando as concepções que orientam o projeto societário que o governo pretende conformar. Estas podem se destinar tanto para a transformação social quanto na manutenção do status quo. Há que se dizer ainda que quando não são impulsionadas pela pressão dos movimentos populares, seja para atendê-los ou seja para acalmá-los, voltam seus esforços para a readequação dos arranjos sociais, e em uma sociedade liberal ou neoliberal, por conseguinte, para a adequação ao sistema produtivo capitalista.

Ainda que na perspectiva racional empresarial da gestão educacional, essa se demonstraria ineficaz, uma vez que seria inviabilizada a adequação dos meios à finalidade precípua da Educação, qual seja a da formação humana e cidadã dos educandos ao convívio democrático (PARO, 2012). O exercício docente eficaz não somente se reveste mas deve consistir na autonomia, que o modelo de controle, denominado neotaylorismo por Laval (2004), se demonstra inadequado às finalidades educacionais, ainda que consideradas em uma perspectivas que encontra o sucesso em uma dimensão mais material.

É justamente na impossibilidade de retirar a autonomia docente, que o controle de qualidade pós-tayloriano propõe um empreendedorismo de si mesmo, incentivando o individualismo, desmobilizando as organizações e exercendo, assim, um controle implícito, ideológico do professor, pelo qual busca-se inculcar os valores, princípios e ideias necessárias à adequação ao sistema produtivo aos docentes, que, uma vez internalizados, deslocam a força de controle para o próprio controlado, que, por não perceber a mão invisível do capitalismo, considera-se um cidadão liberado e por conseguinte, liberal. Dessa forma, a escola passa a atuar como um aparelho de socialização submetido ao capitalismo (LAVAL, 2004), de modo que o 
prosseguimento dos estudos se vincula ao potencial produtivo intelectual do aluno, repercutindo na atual crítica da produtividade acadêmica (vinculada à teoria do capital humano).

Se os conflitos históricos sempre se desenvolveram em volta da disputa contra ou a favor de uma hegemonia moral e de valores socioculturais (LAVAL, 2004), atualmente percebemos o abandono dos apegos aos valores morais em favor dos valores favoráveis a economia, que não implica em um conservadorismo, mas no descompromisso total com um sistema de valores, em prol do rendimento financeiro das instituições, sejam elas conectadas direta ou indiretamente às escolas.

Em que pese o aparente esvaziamento ideológico da escola, essa sem o compromisso com uma formação cidadã e democrática, se transforma em uma arma de opressão sistemático, na qual, o pensamento crítico e reflexivo é não somente desvalorizado mas causa de exclusão. Assim, a lógica empresarial não é somente incompatível pela sua determinação conforme a economia, mas por seus meios não se adequarem às verdadeiras finalidades a que se destina a educação, especialmente naquela realizada pela escola pública.

\subsection{Administração escolar comprometida com a transformação social}

Para Paro (2012), a escola tem um grande potencial revolucionário, quando coloca como objetivo servir de instrumento de superação de dominação e exploração social, ao promover a apropriação do conhecimento historicamente acumulado pelas classes trabalhadores a fim de que desenvolvam a consciência crítica sobre a sociedade em que vivem.

No entanto, a administração escolar atual tem demonstrado uma postura conservadora a favor da classe dominante, pois não realiza ações efetivas para a transformação social e mantém os objetivos das classes desfavorecidas apenas no âmbito dos discursos. A escola se configura como reprodutora das desigualdades sociais ao se submeterem aos desejos da classe dominante, a administração escolar se aproxima da administração empresarial, a qual segue os princípios capitalistas de dominação e controle social para a manutenção do status quo.

Nesse sentido, Paro (2012), destaca que uma escola comprometida com a transformação social, precisa adotar objetivos articulados com os interesses da classe trabalhadora e buscar alcançá-los por meio de processos pedagógicos transformadores, que favoreçam a apropriação do saber e o desenvolvimento da consciência crítica. Seguindo nesta direção, os princípios, métodos e técnicas da administração escolar devem se adequar a estes objetivos.

Assim, para que a administração escolar seja de fato comprometida com a transformação social, ela tem que ser antagônica aos pressupostos da 
administração capitalista, rompendo com o paradigma da dominação e se pautando nos paradigmas de uma escola democrática e comprometida com a transformação social.

No entanto, a racionalidade interna da escola, entendida como a força intelectual da administração escolar, que se proponha à transformação e o devido alinhamento de seus recursos aos seus objetivos não se constituem fora da racionalidade externa à escola. Ao contrário, se seus objetivos se definem antagonicamente ao sistema social vigente, não só é certo que sua racionalidade busca transcender o âmbito escolar, como advém e se constitui a partir dele. Assim, seus objetivos não são neutros, mas historicamente determinados, de modo que, se não rompida com a lógica capitalista, a escola se torna reprodutora da racionalidade externa, atuando como conservadora dos sistema vigente (PARO, 2012).

Uma das maiores dificuldades na persecução dos objetivos alinhados aos interesses das classes trabalhadoras são as limitações impostas pelos órgãos superiores do sistema escolar, que podem atuar em favor da conservação do sistema vigente ao qual servem, inclusive podendo se declarar em favor das classes trabalhadoras em seus currículos, programas, seleção de conteúdos, métodos e equipes enquanto os exclui do poder de decisão sobre eles. Para tanto, é necessário que os educadores desenvolvam uma consciência de classe, rompendo com a lógica capitalista que eleva os interesses privados aos coletivos, de modo a perceber-se enquanto classe trabalhadora, e promover esse movimento de consciência na classe trabalhadora nos pais e na comunidade a que a escola se estende, desvelando os verdadeiros interesses da ideologia dominante e como a instituição escolar dela resulta.

Uma vez alinhados os objetivos da escola à transformação social a que se compromete, para transcender o nível da intencionalidade e se elevar à práxis a fim de concretizá-los, deve-se ter em vista a perseguição dos mesmos, por meio da racionalização dos recursos de forma eficiente, conforme os princípios da administração postulam ${ }^{1}$, com a consciência de que todos os conhecimentos, técnicas e instrumentos referentes ao emprego racional de recursos acumulados historicamente devem ser utilizados com vistas ao progresso no avanço da práxis administrativa escolar.

Conceber a administração como inerentemente conservadora, nega o potencial enquanto sugere alternativas meramente espontaneístas ao modelo vigente, desconsiderando com as causas sociais e econômicas que as determinam. Isso porque a administração se revela conservadora quando, na teoria, adota o pressuposto da administração capitalista, e na prática, ao negligenciar aspectos mais técnicos em favor do privilégio dos aspectos políticos comprometidos com a conservação e dominação social. Deve-se, portanto elevar a práxis espontânea a uma práxis reflexiva, que não

\footnotetext{
${ }^{1}$ Administração entendida como utilização racional de recursos para realização de fins. 
meramente critica a ordem vigente, mas que promove a autoconsciência, consciência da própria da racionalidade do processo na utilização racional dos recursos.

Como forma de delinear a devida persecução dos objetivos, a administração escolar deve desenvolver planos de ação que envolvam os setores escolares e os segmentos da sociedade, rompendo com as práticas adotadas por uma administração autoritária por meio da colaboração, cooperativa, objetivos, vontade coletiva, recíproca, solidária e de forma a consolidar trabalho social com e para a comunidade.

Paro (2012), conclui afirmando que para que se efetive uma administração escolar democrática e voltada aos interesses da classe trabalhadora, não basta que todos participem das tomadas de decisões. As relações têm que ser de mútua colaboração e reciprocidade e estas não são alcançadas do de um dia para o outro, é preciso que elas atitudes vão sendo construídas dia a dia initerruptamente.

\subsection{Protagonismo juvenil na gestão colaborativa}

Apesar do movimento estudantil ainda não ocupar espaço significativo no cenário da democracia brasileira, e, sendo ainda recente o protagonismo juvenil alinhado a uma perspectiva de construção democrática de sociedade, Ferreti, Zibas e Tartuce afirmam que "o discurso da participação ativa dos alunos em sua aprendizagem data, no Brasil, dos anos 20 e 30 do século passado, quando o pensamento de Dewey foi adotado por diversos teóricos da educação" (2004, p. 411). Essa constatação revela que o protagonismo juvenil está intimamente ligado às mudanças no âmbito educacional.

De acordo com a Secretaria de Educação do Estado de Santa Catarina (2008), a participação dos jovens na construção da sociedade está presente em vários períodos históricos do nosso país, desde o período colonial, quando estudantes fundaram um clube secreto para lutar pela independência do Brasil, por meio da publicação de artigos nos jornais da época. Ao passar dos anos, os jovens estudantes foram sentindo a necessidade de se organizarem e no ano de 1937, foi criada a União Nacional dos Estudantes (UNE), entidade que representa os estudantes universitários brasileiros, e em 1948, é fundada a União Brasileira dos Estudantes Secundaristas (UBES), e, dois anos após, é fundada União Catarinense dos Estudantes.

No ano de 1964 os estudantes universitários criaram o Centro Popular de Cultura, o qual produziu várias atividades artísticas, agitando a cultura nacional. No entanto o Brasil sofre um golpe de estado e passa a ser governado por um regime militar, que proíbe as manifestações populacionais e culturais e os estudantes passaram a ser perseguidos e reprimidos.

Embora o Grêmio Estudantil remonte ao período da Ditadura Militar ao lado da inserção dos conselhos escolares, é somente com os movimentos 
pela redemocratização do país na década de 1990 que são emitidos diferentes documentos oficiais, em âmbito federal e estadual no sentido de explicitar e valorizar a participação dos estudantes e suas famílias na democratização da gestão escolar (FERRETI, ZIBAS, TARTUCE, 2004). Os autores colocam que esse reconhecimento conduz à percepção da escola como espaço pedagógico "atraente e desafiador para os jovens, de modo a favorecer seu progresso intelectual, social e afetivo, e, ainda, um espaço democrático, confiável e culturalmente rico para pais e para a comunidade, com vistas a um intercâmbio fecundo entre a escola e o seu entorno." (Ibidem, p. 412).

Foi no ano de 1985, segundo Mendes (2011), que os estudantes ganham o direito se reunirem em Grêmios Estudantis através da Lei Federal no 7398 , que prevê em seu Art. 1을

Aos estudantes de estabelecimentos de ensino de $1^{\circ}$ e $2^{\circ}$ graus fica assegurada a organização de Estudantes como entidades autônomas representativas dos interesses dos estudantes secundaristas com finalidades educacionais, culturais, cívicas esportivas e sociais. (BRASIL, 1985).

Para a autora, "o Grêmio Estudantil é espaço de representação dos alunos na escola; um instrumento que os estudantes possuem para expressar suas reivindicações, e também um espaço de lazer, sociabilidade e política" (MENDES, 2011, p. 16). O meio legal de difusão do protagonismo juvenil no Ensino Médio são as Diretrizes Curriculares Nacionais para o Ensino Médio DCNEM.

Conforme as Diretrizes para Entidades de Gestão Democrática Escolar do Estado de Santa Catarina (2008), o Grêmio Estudantil é a entidade que, na escola, permite que o educando desenvolva e exerça sua cidadania, sendo que exercê-la implica na vontade de reflexão, criatividade, consciência política e comprometimento coletivo num processo que transforma a si e a sociedade. Segundo este documento, o objetivo geral do Grêmio Estudantil é:

[...] participar ativamente na elaboração, execução, avaliação e reelaboração do Projeto Político Pedagógico da Escola, favorecendo o desenvolvimento da consciência crítica da realidade social, da prática democrática, da criatividade e da iniciativa dos alunos, indispensáveis para o exercício da cidadania (SED-SC, 2008, p. 43).

Para tanto são estabelecidos como objetivos específicos:

Defender os interesses dos educandos para que sejam respeitados os seus direitos, bem como para que os mesmos cumpram os seus deveres.

Representar os estudantes nas discussões de possibilidades de ações na escola e na comunidade.

Estabelecer parcerias com a APP e Conselho Deliberativo Escolar para soluções de problemas existentes na escola e demais ações pertinentes ao andamento das atividades escolares.

Contribuir para o exercício da cidadania, possibilitando a atuação do jovem na construção da cultura da paz através de uma sociedade mais justa. 
Contribuir para a dinamização do processo pedagógico discutindo com a comunidade escolar as dificuldades de aprendizagem, repetência, infrequência, evasão e atitudes comportamentais dos alunos, buscando possíveis soluções.

Envolver os pais e a comunidade escolar em ações contínuas sobre temáticas multidisciplinares, como a Educação Fiscal, Educação Ambiental, Educação Sexual, Prevenção ao uso indevido de Drogas e outras de interesse desta comunidade, que devem também estar contempladas no Projeto Político Pedagógico.

Promover o envolvimento do aluno no ambiente escolar, através de atividades pedagógicas, culturais, recreativas e esportivas.

Respeitar as autoridades constituídas tendo-os como parceiros (SED-SC, 2008, p. 43).

Se por um lado, apresenta-se um rol que permite uma atuação estudantil relativamente ampla, percebe-se ao mesmo tempo certa limitação ao poder estudantil, se limitando ao respeito às autoridades constituídas. Tal limitação vem acompanhada da referência à parceria, se mostrando contraditória a uma perspectiva hierárquica subentendida pela enunciação à autoridade.

A palavra "respeito" abrange múltiplos significados, sendo estabelecidos seus sentidos de forma diferente por cada indivíduo. A fim de se orientar por uma perspectiva de respeito mútuo, é importante destacar que a mera discordância de percepções e os conflitos de valores derivados dessas inter-relações devem ser mediados, respeitando-se as diferentes culturas, sendo cada indivíduo considerado como sujeito de direitos.

Tal consideração se faz necessária dado o processo histórico-políticosocial que marca o protagonismo estudantil brasileiro com reminiscências de sua subjugação ao autoritarismo estatal e escolar, reduzindo-o a uma participação passiva no processo educativo tomado em sentido estrito e amplo. Ou seja, por muito tempo o estudante foi reduzido a um expectador do ensino, entendido como transmissão de conhecimentos pré-definidos conforme o entendimento curricular, refletindo tal papel em sua percepção enquanto cidadão. A percepção da educação enquanto processo de ensinoaprendizagem com vistas à formação humana em sua totalidade, coloca o estudante como sujeito central desse processo.

De acordo com Ferreti, Zibas e Tartuce (2004), a etimologia do termo protagonismo assume sentido de evidência, remontando à palavra grega referente ao ator principal de uma peça. Nesse sentido, percebe-se que a noção de protagonismo vinculada ao estudante, tem por objetivo afirmar o papel do estudante à frente do processo educacional. Assim, protagonismo estudantil não se refere somente a atuação dos estudantes, mas ao reconhecimento do seu papel como sujeitos de direitos e deveres. Nesse sentido, Costa, 2001; Barrientos, Lascano, 2000; Konterlinik, 2003 (apud FERRETI, ZIBAS TARTUCE, 2004), vinculam o protagonismo juvenil à formação cidadã. 
Salienta-se que a questão da terminologia do protagonismo estudantil também encontra crítica no sentido de que promoveria a responsabilização dos jovens à persecução dos seus direitos (SOUZA, 2006). Assim entendemos que o protagonismo juvenil não se refere apenas a atuação do estudante dentro da escola, mas também a sua intervenção na sociedade como cidadãos de direitos e deveres. Mendes (2011), afirma que hoje em dia a muitos jovens não se interessam e não tem motivação para envolver-se com questões políticas amplas. No entanto, há jovens que ligam - se a agremiações e partidos com a intenção de fazerem reivindicações e protestos de caráter político sobre questões da sociedade em geral. Essa concepção revela a percepção do diálogo da racionalidade interna da escola à racionalidade externa, por meio da qual orientam-se os processos educativos a partir da realidade social em que se insere a escola, e a fim de promover a transformação social nessa mesma realidade.

Afinal, qual o papel dos educadores na promoção do protagonismo estudantil sendo esse papel inerente aos jovens estudantes? De acordo com Veiga, "é preciso desencadear um movimento no sentido de organizar o trabalho pedagógico com base na concepção de planejamento participativo e emancipador (1998, p. 124).

Ainda, de acordo com Schmidt (2001, p. 80), "a escola poderia ser considerada, a um primeiro olhar, a única entre as agências de socialização que se ocupa explicitamente da transmissão intencional de atitudes políticas." (lbidem). O autor explica que devido ao ensino se caracterizar como a "transmissão planejada e sistemática de conhecimentos acerca da sociedade e do mundo" (Ibidem), é na sala de aula em que é discutida a realidade política e as possíveis formas de inserção na vida sociopolítica, sendo o conhecimento político das sociedades modernas associado à escolaridade.

Quando não há consciência e intencionalidade nesse processo, a escola se configura como reprodutora da ordem vigente, e, portanto, do status quo, não cumprindo com seu papel de transformadora da realidade social (PARO, 2012). Ainda, Schmidt (2001), afirma que as relações estabelecidas dentro da escola tanto entre estudantes, educadores e entre estudantes e educadores, como entre as atividades, conteúdos e formas pela qual se constitui o ambiente escolar também ensinam.

Nesse sentido, a escola encontra seu papel na efetivação do direito à ampla participação estudantil na vida escolar e na promoção da conscientização dos alunos acerca da importância de seu protagonismo estudantil, pois conforme Mendes (2011), o Grêmio Estudantil é um espaço de encontro juvenil, de sociabilidade, de trocas de experiências e de informações, onde os jovens desenvolvem atividades e vão aprendendo a negociar. Logo, segundo a autora, com o contato que estabelecem com os adultos no espaço escolar, esses jovens aprendem a "lidar com os conflitos de valores e geracionais" (MENDES, 2011, p. 19). 


\section{METODOLOGIA}

A pesquisa é de abordagem qualitativa-descritiva. Segundo Chizzotti (2003, p. 96), "a pesquisa qualitativa é aquela pesquisa que trabalha com interpretações, comparações e resultados que não podem ser mensuráveis numericamente".

O tipo da pesquisa é bibliográfica, na acepção de Severino (2007), a pesquisa bibliográfica é aquela que se realiza a partir do registro disponível, decorrente de pesquisas anteriores, em documentos impressos, como livros, artigos, teses, ou seja, se utiliza de dados ou categorias teóricas já trabalhadas por outros pesquisadores e devidamente registrados.

Para o desenvolvimento da pesquisa foi aplicada a análise de documentos por meio da técnica de análise de conteúdo do relatório de estágio e do projeto de intervenção. Para Bardin, "a análise de conteúdo é um conjunto de técnicas de análise das comunicações, a qual não se trata de um instrumento, mas de um leque de apetrechos, ou, com maior rigor [...]" (2009, p. 30). Desta forma, para a organização e análise dos documentos, seguimos os três polos de análises proposto por Bardin (2009), a saber: i) pré-análise dos documentos selecionado ii) exploração e leitura dos documentos; e iii) tratamento e análise dos resultados, ou achados da pesquisa.

O relatório de estágio denominado Protagonismo juvenil em filmes: uma proposta de gestão e o projeto de intervenção intitulado Grêmio Estudantil: uma oportunidade de aproximação entre gestão escolar e estudantes da Escola de Educação Básica Professor José Arantes contemplou a caracterização da escola estadual onde o estágio foi desenvolvido, reunindo informações, tais como: i) história, estrutura física, dimensão administrativa, plano de gestão da equipe de direção, metas e estratégias do plano de gestão contemplados no Projeto Político Pedagógico da escola; ii) fundamentação teórica acerca da gestão democrática; iii) mecanismos da gestão democrática desenvolvidos pela escola com pais, estudantes, professores, comunidade escolar; iii) concepção filosófica da unidade escolar; e planejamento do desenvolvimento do projeto de intervenção no cotidiano escolar.

A partir da inserção propiciada pelo estágio, na qual realizou-se a observação da atuação da gestão escolar e realizou-se um diagnóstico da escola E.E.B. Professor José Arantes, de 11 a 18 de setembro de 2017, totalizando 24 (vinte e quatro) horas. Em consequência, o projeto de intervenção analisado foi planejado por uma dupla estudantes, do $8^{\circ}$ semestre, na disciplina de Estágio Supervisionado em Gestão, do Curso de Licenciatura em Pedagogia do IFC - Campus Camboriú e contemplou a seguinte organização: tema; problema; objetivo geral e objetivos específicos; 
justificativa; metodologia; referencial teórico acerca da temática Grêmio Estudantil; planejamento detalhado das atividades propostas; cronograma de execução; e considerações finais.

A orientação e supervisão do Estágio Supervisionado em Gestão foram realizadas de forma conjunta entre a professora orientadora do IFC - Campus Camboriú que acompanhou presencialmente o estágio e a supervisora da E. E. B. Professor José Arantes. Após o térmico do estágio na escola, todos as escolas que receberam os estudantes, foram convidados e prestigiaram a socialização e apresentações das atividades desenvolvidas, envolvendo professores e estudantes do IFC, professores e estudantes do magistério e professores e gestão da rede municipal e estadual de Camboriú e região. Ao final do estágio, os estudantes cumpriram ao final 75 (setenta e cinco) horas.

Na próxima seção, ocorre a apresentação da descrição e análise dos documentos selecionados, evidenciando as ações e o planejamento Estágio Supervisionado em Gestão realizado pela dupla de estudantes do Curso de Licenciatura em Pedagogia do IFC - Campus Camboriú com as propostas de atividades de intervenção.

\section{$4 \quad$ RESULTADOS E DISCUSSOES}

A partir da inserção propiciada pelo Estágio Supervisionado em Gestão Escolar, do curso de Licenciatura em Pedagogia, na qual realizou-se a observação da atuação da gestão escolar e realizou-se um diagnóstico da escola E.E.B. Professor José Arantes, de 11 à 18 de setembro de 2017, totalizando 24 (vinte e quatro) horas. Em conjunto com a direção da escola, chegou-se à conclusão de que a comunidade escolar necessita de uma orientação sobre a importância do protagonismo juvenil, devido a intenção de alguns alunos de montar um Grêmio Estudantil na instituição. A gestão apontou a importância na tomada de consciência pelos alunos no processo de implementação do Grêmio Estudantil para que não se dê de forma mecânica, sem sentido para os jovens. Entendemos que o Grêmio Estudantil, enquanto órgão de representatividade discente é entidade fundamental de uma gestão participativa orientada pelos princípios democráticos.

Para que ele seja de fato uma organização estudantil que busque os interesses dos jovens da escola e participe das tomadas de decisão da gestão, elaboramos este projeto de intervenção com a intenção de oferecer subsídios para que toda comunidade escolar no sentido da compreensão do que é e qual a importância do Grêmio Estudantil, com vistas à percepção dos jovens enquanto sujeitos ativos do processo de ensino-aprendizagem em que estão inseridos e à conscientização acerca do protagonismo juvenil na gestão colaborativa. 
Tendo-se em vista que a sociedade moderna é marcada pelo avanço tecnológico que atrai principalmente os jovens para uma forma de comunicação audiovisual, acreditamos que a promoção de um ciclo de mostras de filmes possam ter maior alcance da atenção dos jovens, além de desenvolver a percepção estética, artística, poética, que, por sua vez promovem a sensibilização dos jovens acerca de questões que diretamente os envolvem. Ainda, buscamos materiais que encontram-se disponíveis gratuitamente na internet de modo a facilitar o acesso aos mesmo.

Deste modo, o projeto de intervenção acerca do tema protagonismo juvenil na gestão colaborativa, teve como objetivo geral: conscientizar a comunidade escolar acerca da importância do protagonismo juvenil por meio do reconhecimento dos jovens enquanto sujeitos de direitos. $E$ os seguintes objetivos específicos: enxergar os estudantes como protagonistas do processo educativo e da construção da sociedade; promover a inclusão na escola por meio do acolhimento das identidades e diferenças; conscientizar o corpo docente acerca do seu papel enquanto mediadores da formação cidadã dos estudantes; orientar o processo de implementação do Grêmio Estudantil na E.E. B. Professor José Arantes. Constituindo-se assim, o seguinte problema: como promover o processo de conscientização acerca do protagonismo juvenil na escola respeitando-se a autonomia dos estudantes?

\subsection{Metodologia proposta para o desenvolvimento do projeto de intervenção}

Em um primeiro momento toda a equipe de gestão deverá se reunir para definir questões específicas deste projeto como por exemplo as datas, os locais e a forma como será aplicada cada ação proposta neste documento.

$\mathrm{Na}$ reunião, poderá ser entregue o presente projeto a fim de que todos tenham conhecimento das propostas e do estudo bibliográfico acerca do tema protagonismo juvenil e a constituição de Grêmio Estudantil.

No segundo momento a gestão pode começar a pôr em prática a primeira ação, que consiste em reunir todos os docentes e servidores da instituição para conscientizar e esclarecer sobre a proposta de constituir uma Grêmio Estudantil na Escola de Educação Básica Professor José Arantes. Nessa reunião os docentes e servidores deverão compreender sobre a importância da participação dos estudantes na gestão da escola de forma organizada e orientada para exercerem a cidadania na busca de seus direitos e no exercício de seus deveres.

No terceiro momento a equipe gestora precisa organizar a sessão cinema que consiste na exibição de um ou mais filmes que tratam sobre a temática do protagonismo juvenil e participação do estudante nas tomadas de decisão da gestão escolar. Essa sessão cinema deverá ser realizada com toda a comunidade escolar, e por isso deverá ser realizada em um local 
amplo ou em espaços menores, porém em repetidas vezes para que contemple a todos os alunos, servidores e professores.

No quarto momento a gestão irá e reunir os alunos e apresentará a eles uma explicação sobre o que é um Grêmio Estudantil, quantos membros deve possuir, como e qual a importância da sua atuação na escola e como deve ocorrer a eleição dos membros participantes. Caso na instituição não haja algum funcionário que possua os conhecimentos necessários para realizar essa palestra, a gestão pode convidar um ou mais membros da União Catarinense dos Estudantes para conversar com os alunos. Sugestão: Convidar um integrante da União Nacional dos Estudantes (UNE) ou da União Catarinense dos Estudantes (UCE). Sugerimos o membro da UCE e acadêmico do Instituto Federal Catarinense - Campus Camboriú.

\subsection{Planejamento das atividades propostas acerca da mostra de filmes}

Planejamento das atividades propostas para o projeto de intervenção intitulado Grêmio Estudantil: uma oportunidade de aproximação entre gestão escolar e estudantes da Escola de Educação Básica Professor José Arantes.

\subsubsection{Primeira atividade: reunião com docentes e servidores}

Pauta: conscientização docente.

Descrição da atividade a ser desenvolvida:

Reunião com todos os docentes, gestores e servidores da instituição a fim de ser esclarecida a intencionalidade da proposta.

Material: textos sobre movimentos estudantis e protagonismo juvenil.

Ambiente: sala dos professores

Participantes: professores, gestores e servidores.

Sistematização:

Fazer uma ata a fim de registrar as contribuições dos professores acerca das formas de abordagem do problema e suas visões sobre a temática em si, uma vez que o posicionamento do docente interfere diretamente na formação dos alunos, seja no sentido de concordância ou oposição. Ainda nesse sentido, é importante que sejam incentivadas as argumentações dos docentes acerca da temática a fim de que o discurso não seja tomado de forma superficial e inconclusiva.

Levantar os conhecimentos dos educadores acerca do que é o Grêmio Estudantil, a história dos movimentos estudantis;

Introduzir a temática após a leitura do material sugerido e outros pesquisados, trazendo o histórico dos movimentos estudantis; 
Promover o debate sobre os assuntos, levantando as histórias de vida dos professores acerca de sua juventude: se participaram de grêmios ou outros tipos de associação e como compreendem o protagonismo juvenil;

É importante que os gestores coloquem a importância da temática aos professores e da colaboração de todos no sentido de ser percebida a temática de forma transversal;

Propor aos professores a abordagem da temática em suas disciplinas conforme a especificidade de suas áreas, abordando-se a história dos movimentos estudantis pelo mundo e do protagonismo juvenil brasileiro o qual não encontra área a que sua atuação seja limitada (Ex: projetos ambientais, artísticos, culturais, sociais etc);

Introduzir a proposta da exibição de filmes - documentários aos professores e discutir a possibilidade de um ciclo de exibição de filmes sobre protagonismo juvenil.

\subsubsection{Segunda atividade: mostra de filmes para a comunidade escolar}

Pauta: conscientização acerca do protagonismo juvenil.

Descrição da atividade a ser desenvolvida:

Fazer um convite a toda a comunidade escolar, com foco nos alunos, por meio de cartazes, publicação em plataforma virtual da escola e passando nas salas. Sugere-se sejam convidados possíveis alunos interessados na criação do Grêmio Estudantil desde essa fase;

Para a exibição dos filmes o material necessário é: notebook; projetor; caixa de som; e os filmes.

Quadro 1: Sinopses e resenhas dos filmes sugeridos

Histórias de mobilização Juvenil - Frutos do Brasil

Disponível em: <https:// youtu.be/Qi8Rwp4Sdr0>

Documentário dirigido pela jornalista Neide Duarte com o objetivo de promover a participação juvenil e o debate acerca da condição vivida por jovens brasileiros. No documentário, jovens oriundos de diversas regiões brasileiras relatam como mudaram suas vidas. Apesar da baixa qualidade gráfica, o que se justifica por não tratar-se de um filme tão recente, acreditamos que a exibição do filme "Histórias de mobilização Juvenil" seja enriquecedora, primeiramente, por ressaltar a autonomia dos jovens por suas próprias vidas e de suas comunidades, de modo a promover o processo de autoconsciência (PARO, 2012), propiciando uma efetiva apreensão da percepção dos efeitos da participação democrática pelos indivíduos.

Em segundo lugar, por meio de um processo inspirado em valores democráticos, com vistas à valorização do protagonismo juvenil. Primeiramente, foi realizada uma consulta pública com o objetivo de identificar projetos desenvolvidos por grupos de jovens em suas comunidades.

Em terceiro lugar: Tendo-se em vista que foram inscritos mais de 150 grupos que desenvolvem projetos nos mais diferentes temas: meio ambiente, educação, 
desenvolvimento comunitário, o documentário provoca a desconstrução da resistência às propostas interdisciplinares e transdisciplinares nos processos educativos escolares, sobretudo pela limitação curricular. Por fim, acreditamos que o processo dentro do qual o documentário se desenvolveu e os resultados alcançados sejam inspiradores para a construção de projetos que se desenvolvam de modo a constituir novos projetos, integrando uma rede de ações que se inicie a partir de iniciativas e se expanda para esferas superiores. Isso porque o documentário se originou a partir de outro projeto: Frutos do Brasil - Juventude em Debate, desenvolvido pela Agência de Mobilização Social (Aracati), envolveu os jovens a partir de seu próprio protagonismo, resultou em uma versão publicada em livro, culminando na integração do projeto Frutos do Brasil ao Programa Cultura Viva do Ministério da Cultura.

\section{Quando sinto que já sei - Catarse (2014) - 1h18min}

Disponível em: <http://www.videocamp.com/pt/movies/quando-sinto-que-ja-sei>

Documentário projeto independente idealizado por Antônio Sagrado Lovato que registra por meio de depoimentos de estudantes, educadores, pais, e outros membros da comunidade, práticas educacionais inovadoras que propõe mudanças no modelo tradicional escolar e que estão ocorrendo em escolas brasileiras. Acreditamos que a obra promove o encontro entre instituição educacional e estudante ao apresentar diferentes concepções de ensino e gestão, alinhados a princípios democráticos adotados na Escola da Ponte em Portugal - referência de um modelo escolar mais democrático, inclusivo e intercultural. $O$ documentário, além de possuir uma ótima qualidade gráfica, oferece subsídios metodológicos para ser repensada a prática escolar com a uma efetiva participação estudantil e comunitária, por meio da valorização da autonomia do aluno, de estratégias colaborativas e da perspectiva da solidariedade.

\section{Pro dia nascer feliz - João Jardim (2005) - 1h28min.}

Disponível em: <https://www.youtube.com/watch?v=29zuO59qYE8>

Documentário que promove um encontro de perspectivas, sonhos, desafios e as desigualdades vividas por jovens de diferentes cidades e contextos sociais. A expressão dos jovens por meio de entrevistas e produções poéticas permite ao espectador a aproximação do olhar aos indivíduos sujeitos do processo educativo e de como suas vivências e condições subjetivas e materiais influenciam em sua formação discente.

\section{Últimas Conversas - Eduardo Coutinho - (2005) - 1h28min}

Disponível em: <https://www.youtube.com/watch?v=HVa76ZjtyEw>

Último filme realizado por Eduardo Coutinho reúne entrevistas com jovens estudantes da rede pública do Rio de Janeiro acerca de seus pensamentos, experiências e expectativas profissionais e de vida. Acreditamos que o filme promove uma maior aproximação do olhar dos educadores aos estudantes, suas realidades, medos, anseios, traumas, e, aos alunos, a expansão do olhar sobre si mesmos, permitindo-Ihes conhecer outras possibilidades acerca de suas próprias vidas e dar vazão aos seus próprios sentimentos. Além de possuir ótima qualidade gráfica e sonora, o documentário possui uma estética intimista e fria ao mesmo tempo, refletindo a insegurança da adolescência em um país marcado pela desigualdade social e conflitos culturais.

\section{Memórias do movimento estudantil: Ou Ficar A Pátria Livre Ou Morrer Pelo Brasil/O afeto que se encerra em nosso peito juvenil" (2007) - Silvio Tendler - 01h06min}

Disponível em: <http://www.videocamp.com/pt/movies/memorias-do-movimentoestudantil-o-afeto-que-se-encerra-em-nosso-peito-juvenil>

Disponível em:<https://www.youtube.com/watch?v=S1CWdnWYkow> 
Documentário desenvolvido entre os anos de 2004 e 2007 que reúne registros pessoais de pessoas envolvidas no movimento estudantil. A primeira parte foca na cronologia do movimento estudantil desde 1937, enquanto que a segunda parte aborda o processo de constituição do protagonismo juvenil, destacando as atividades culturais como músicas, poesias e peças teatrais.

\section{Fonte: Elaboração das autoras}

Ambiente para a apresentação: os filmes podem ser exibidos na quadra de esportes, sendo projetado por meio de um data show. Caso não seja possível a exibição dos filmes em um ambiente único, sugere-se que sejam exibidos em cada turma, comportando em diferentes salas os gestores e servidores da instituição.

Participantes: alunos, professores, gestores e servidores.

Sistematização:

Sugere-se sejam organizadas mesas com educadores cujas áreas encontrem afinidades com os filmes exibidos a fim de promover um debate na escola.

Após a exibição de cada filme, sugere-se seja feita a problematização de cada filme assistido, perguntando-se se gostaram, do que gostaram, do que não gostaram, o porquê, o que sentiram, o que pensam.

O mediador, pode partir das resenhas escritas acima para propor o diálogo acerca das temáticas envolvidas.

\subsubsection{Terceira atividade: palestra sobre a constituição e funções de um Grêmio Estudantil}

Pauta: conscientização acerca do que é e como se constitui um Grêmio Estudantil.

Descrição da atividade a ser desenvolvida: todos os alunos serão reunidos para assistirem a uma palestra sobre a importância e as atribuições de um Grêmio Estudantil.

Quadro 2: Roteiro para a implementação do Grêmio Estudantil

\begin{tabular}{|l|l|}
\hline $\begin{array}{l}\text { 10 passo } \\
\text { A comissão }\end{array}$ & $\begin{array}{l}\text { O grupo interessado em formar o Grêmio, deve divulgar a proposta na } \\
\text { escola e convidar os alunos e os representantes de classe (se houver) } \\
\text { para debater sobre o Grêmio Estudantil, seu papel dentro da escola, } \\
\text { como funciona um Grêmio e sua importância. Desta reunião deve ser } \\
\text { formada uma COMISSÃO PRÓ-GRÊMIO. Que será o grupo que } \\
\text { coordenará o processo de fundação do Grêmio. Vai elaborar uma } \\
\text { proposta de Estatuto e convocar a assembleia geral que vai fundar o } \\
\text { Grêmio da escola. }\end{array}$ \\
\hline $\begin{array}{l}\text { A passembleia } \\
\text { geral }\end{array}$ & $\begin{array}{l}\text { A Comissão Pró-Grêmio convoca todos os alunos da escola para } \\
\text { participar da ASSEMBLEIA GERAL. Essa convocação será feita com } \\
\text { cartazes informando a data, o local e a pauta da assembleia geral e } \\
\text { passagem em sala de aula em todos os turnos. Na assembleia geral, }\end{array}$ \\
\hline
\end{tabular}




\begin{tabular}{|c|c|}
\hline & $\begin{array}{l}\text { decidem-se o nome do Grêmio, o período de campanhas das chapas, a } \\
\text { data das eleições e aprova-se o Estatuto do Grêmio. Na Assembleia } \\
\text { também se definem os membros da COMISSÃO ELEITORAL. } \\
\text { *A assembleia geral deverá ser registrada em ata. }\end{array}$ \\
\hline $\begin{array}{l}3^{\circ} \text { passo } \\
\text { A comissão } \\
\text { eleitoral }\end{array}$ & $\begin{array}{l}\text { A comissão eleitoral deve redigir o edital da eleição com as regras do } \\
\text { processo eleitoral, dentro das regras do estatuto. Divulgar o edital } \\
\text { fixando-o em locais visíveis pelos estudantes e passando em sala de } \\
\text { aula. Disponibilizar os formulários para inscrição de chapas. Receber } \\
\text { dos alunos a inscrição das chapas de acordo com o determinado no } \\
\text { edital. A comissão eleitoral promove debates entre as chapas, abertos a } \\
\text { todos os alunos. }\end{array}$ \\
\hline $\begin{array}{l}4^{\circ} \text { passo } \\
\text { As chapas e as } \\
\text { campanhas }\end{array}$ & $\begin{array}{l}\text { Os alunos se reúnem e formam as CHAPAS que concorrerão na } \\
\text { eleição. Eles devem apresentar suas ideias e propostas para o ano de } \\
\text { gestão no Grêmio Estudantil. As chapas inscritas devem divulgar suas } \\
\text { propostas nas salas de aula, panfletos, cartazes e faixas espalhados na } \\
\text { escola. É importante que as chapas participem dos debates promovidos } \\
\text { pela comissão eleitoral. Conversem com o maior número de estudantes } \\
\text { possível sobre o Grêmio e as propostas de sua chapa para o Grêmio } \\
\text { Estudantil. }\end{array}$ \\
\hline $\begin{array}{l}5^{\circ} \text { passo } \\
\text { A eleição }\end{array}$ & $\begin{array}{l}\text { A comissão eleitoral organiza a ELEIÇÃO. Prepara as listas de votação, } \\
\text { lacra as urnas juntamente com (02) dois representantes de cada chapa } \\
\text { e dá início à votação. Finalizada a votação a contagem será feita pelos } \\
\text { representantes da comissão, acompanhados de (02) dois } \\
\text { representantes de cada chapa e, eventualmente (caso os estudantes } \\
\text { vejam necessidade), dos coordenadores pedagógicos da escola. No } \\
\text { final da apuração, a comissão eleitoral deve fazer uma ata de eleição } \\
\text { para divulgar os resultados. Afixando a ata de eleição em locais de fácil } \\
\text { visibilidade na escola. }\end{array}$ \\
\hline $\begin{array}{l}\text { 60 passo } \\
\text { A posse }\end{array}$ & $\begin{array}{l}\text { A comissão eleitoral organiza a cerimônia de POSSE DA DIRETORIA } \\
\text { do Grêmio (quem cuidará do que no Grêmio Estudantil). Sendo } \\
\text { empossada a nova diretoria do Grêmio Estudantil deve iniciar os } \\
\text { trabalhos e fazer de tudo para cumprir com o que foi prometido durante } \\
\text { a campanha eleitoral. E comunicar às entidades estudantis da rede da } \\
\text { UBES (União Brasileira dos Estudantes Secundaristas) sobre a eleição } \\
\text { do Grêmio. }\end{array}$ \\
\hline Próximo ano & * A cada ano, reinicia-se o processo eleitoral a partir do 3ำ passo. \\
\hline
\end{tabular}

Fonte: BRASIL (2010)

Materiais necessários: o microfone; a caixa amplificadora.

Ambiente: Pátio da escola ou quadra de esportes.

Participantes: alunos, professores, gestores e servidores.

Sistematização: após a fala do palestrante, pode ser aberto um momento para que os estudantes façam suas perguntas, estruturando assim um momento de diálogo aberto onde todas as dúvidas possam ser esclarecidas. Por meio desse diálogo a equipe gestora também poderá 
perceber se as demais ações foram suficientes para contemplar os conhecimentos necessários para a constituição do Grêmio Estudantil.

Encerramento:

A equipe gestora pode providenciar e distribuir materiais impressos que informem sobre o movimento de constituição do Grêmio Estudantil e da importância da participação responsável e consciente dos estudantes na gestão da E. E. B. Professor José Arantes. Também podem ser distribuídas cartilhas que apresentem os objetivos, normas e atribuições de um Grêmio Estudantil.

Portanto, acredita-se que o projeto de intervenção proposto se constitua como uma primeira etapa de um processo de conscientização e promoção do interesse dos estudantes em sua participação efetiva na comunidade escolar. Por essa razão os filmes são propostos no sentido de aproximar o olhar dos educadores à realidade juvenil brasileira e a percepção dos estudantes enquanto cidadãos e sujeitos de direitos responsáveis pelos processos educativos em que são inseridos, bem como de oferecer subsídios para a promoção de processos educativos mais democráticos, inclusivos e dialógicos.

\section{CONSIDERAÇÕES FINAIS}

Por meio do Estágio Supervisionado em Gestão foi possível compreender as especificidades dos processos de organização internos da uma escola e como se dá a relação entre suas racionalidades interna e externa, permeadas por desafios diários que requerem competência e dinamismo em sua resolução.

O tema proposto pela escola para o projeto de intervenção nos possibilitou refletir acerca da importância do Grêmio Estudantil como entidade da gestão democrática, pois possibilita que os jovens sejam protagonistas da luta pelos direitos dos cidadãos e da transformação social.

Assim, a experiência revelou que, por meio do reconhecimento dos jovens como parte da gestão escolar, aproxima os jovens da percepção de seu papel ativo no processo educativo e promove a construção da escola enquanto espaço democrático de construção de uma sociedade mais justa e democrática.

\section{REFERÊNCIAS}

BARDIN, L. Análise de Conteúdo. Lisboa, PT: 70, 2009.

BRASIL. Lei no. 7398 de 04 de novembro de 1985. Dispõe sobre a organização de entidades representativas dos estudantes de $1^{\circ}$ e $2^{\circ}$ graus e 
dá outras providências. Brasília, DF: Congresso Nacional, 1985.

Senado Federal. Grêmio livre: 25 anos de legalidade. Brasília:

Senado Federal, Gabinete do Senador Inácio Arruda. 2010. 41 p. Disponível: <https://www2.senado.leg.br/bdsf/bitstream/handle/id/385450/Gremio\%20Livr e.pdf?sequence $=1>$

CHIZZOTTI, A. Pesquisa em ciências humanas e sociais. São Paulo: Cortez, 2003.

COSTA, A. C. G. Tempo de servir: o protagonismo juvenil passo a passo; um guia para o educador. Belo Horizonte: Universidade, 2001.

FERRETTI, C. J.; ZIBAS, D. M. L. ZIBAS; TARTUCE, G. L. B. P. Protagonismo juvenil na literatura especializada e na reforma do Ensino Médio. Cadernos de Pesquisa, v. 34, n. 122, p. 411-423, maio/ago. 2004.

MENDES, F. B. Um grêmio estudantil mais politizado: formas de engajamento e construção identitária em um grêmio estudantil. Porto Alegre, 2011.

PARO, V. H. Administração escolar: introdução crítica. 16. ed. São Paulo: Cortez, 2010.

SANTA CATARINA. Secretaria de Estado da Educação e do Desporto. Diretoria de Ensino Fundamental/Diretoria de Ensino Médio/Diretoria de Planejamento. Entidades de gestão democrática escolar: diretrizes. 4. Florianópolis, 2008.

SCHMIDT, J. P. Juventude e política no Brasil: a socialização política dos jovens na virada do milênio. Santa Cruz do Sul: EDUNISC, 2001.

SEVERINO, A. J. Metodologia do Trabalho Cientifico. 23a ed. São Paulo: Cortez, 2007.

SOUZA, R. M. de. 0 discurso do protagonismo juvenil. 2006. 351 f. Tese (Doutorado) - Curso de Faculdade de Filosofia, Letras e Ciências Humanas, Departamento de Sociologia, Universidade de São Paulo, São Paulo, 2006. Disponível em: <www.teses.usp.br/teses/disponiveis/8/8132/tde-25042007115242/.../tese_regina.pdf>. Acesso em: 03 nov. 2017.

VEIGA, I. P. A. As Instâncias Colegiadas da Escola. IN: Escola: espaço do Projeto Político Pedagógico. Campinas/SP: Papirus, 1998. 